Palimpsesto Vol. 10, № 17 (enero-junio, 2020): 180-196

Universidad de Santiago de Chile, ISSN 0718-5898

Diego Eduardo Niemetz

Universidad Nacional de Cuyo/CONICET

diegoniemetz@gmail.com

\title{
Sobre el testimonio, la ficción y la posmemoria como promesas de redención. Tres textos en el centenario de la Semana Trágica
}

\section{On testimony, Fiction and Postmemory as Promises of Redemption. Three Texts in the Centenary of the Tragic Week}

\begin{abstract}
Resumen
En enero de 1919 se produjeron los violentos acontecimientos que pasarían a la historia bajo la denominación de "Semana Trágica", considerada por algunos estudiosos como el primer pogrom antisemita de América Latina. Dichos eventos han sido objeto de análisis desde distintos puntos de vista y han suscitado, además, muchas especulaciones en torno a la memoria y al olvido de la sociedad en general y de la colectividad judía en particular.

Este trabajo propone un recorrido por una serie de textos que abordan el tema con una dinámica que entrecruza el testimonio, la memoria y la ficción, a través de una variedad de recursos complejos. No se busca analizar obras que meramente tematizan la Sema Trágica, sino aquellas que ponen en juego la memoria personal y que se mueven por sobre la estrecha (y muchas veces endeble) frontera entre el recuerdo, la identidad y la ficción. El estudio parte de Koshmar (Pesadilla) de Pinie Wald (publicado originalmente en idish en 1929). Se trata de un texto que ya es una referencia ineludible sobre el asunto y que ha sido presentado por algunos críticos como un antecedente del género de la no-ficción argentina (fue reeditado en 2019, con motivo del centenario de los hechos allí narrados), para luego estudiar otras dos obras producidas más recientemente, que recuperan esos hechos y que explotan las porosidades entre lo recordado, lo heredado y lo imaginado: El arresto (2001) de Perla Suez y María Domecq (2007) de Juan Forn.
\end{abstract}

Palabras claves: semana trágica, koshmar, antisemitismo, memorias, autoficción.

\footnotetext{
Abstract

In January 1919 took place the violent events that would be known under the name of "Tragic Week" (considered by some scholars as the first antisemitic pogrom in Latin America). These events have been the object of analysis from different points of view and have also generated many speculations about
} 
memory and oblivion of society in general and in the Jewish community in particular.

This paper considers three texts that approach the subject with a dynamic that interweaves testimony, memory and fiction, through a variety of complex resources. In other words, we do not seek to analyze works that merely thematize the "Tragic Week", but those that put personal memories in scene and that move over the narrow (and often slippery) border between memory, identity and fiction. The study starts from Koshmar (Nightmare) by Pinie Wald (originally published in Yiddish, in 1929). This text is an unavoidable reference on the matter and has been presented by some critics as an antecedent of Argentine non-fiction (it was reissued in 2019, on the occasion of the centenary of the events narrated). Then will consider more recently produced works, that recover those facts trough the porosities between the remembered, the inherited and the imagined: El arresto (2001) by Perla Suez and María Domecq (2007) by Juan Forn.

Keywords: tragic week, koshmar, anti-semitism, memories, self-fiction.

\section{El pogrom de 1919 y la controversia historiográfica}

El conjunto de sucesos de lo que se conoce como la Semana Trágica, ha sido revisitado y discutido por la literatura en numerosas ocasiones desde su acaecimiento, hace exactamente cien años. El objetivo central de las páginas que siguen es proponer un recorrido por tres obras que, si bien se refieren al tema desde diferentes ángulos y con intenciones diversas; tienen, además, la particularidad de abordar la tensión que surge entre memoria, recuerdo y ficción, en torno a los hechos de 1919.

El campo de la historiografía que ha estudiado el tema se configura, en base a sus contrapuntos, como una controversia historiográfica, tal y como la ha caracterizado Enzo Traverso en La historia como campo de batalla. La primera de esas posiciones antagónicas es la que busca justificar la represión considerándola una reacción defensiva frente a una presunta conjura judeo-maximalista, que amenazaba a la Nación argentina. Por ejemplo, en una fecha tan posterior a los hechos como el año 1986, Federico Rivanera Carlés ${ }^{1}$ calificaba los desmanes como "la insurrección subversiva más importante del país" y seguía sosteniendo la hipótesis conspirativa sustentada en la asociación bolchevismo-judaísmo, que viene siendo enarbolada por el sector nacionalista incluso desde antes de 1919. En las primeras páginas de su libro El judaísmo y la Semana Trágica: la verdadera historia de los sucesos de enero de 1919, puede leerse:

Ya es tiempo de conocer la verdad. Ella nos mostrará de modo irrebatible el carácter subversivo del movimiento que se originó en la huelga de Vasena y el papel protagónico

\footnotetext{
${ }^{1}$ Cómo él mismo lo expresa, su vínculo con la Semana Trágica es familiar: entre otros, el libro está dedicado a "mi abuelo, el entonces teniente coronel Ernesto Rivanera, que en la Semana Trágica luchó en Santa Fe al mando de sus tropas contra los enemigos de Dios y de Argentina. A mi tío abuelo, Manuel Carlés, fundador y jefe de la Liga Patriótica Argentina, que encarnó la reacción civil contra el levantamiento apátrida. A mi padre, Raúl Rivanera Carlés, a la sazón de 20 años, quien durante los sucesos formó parte de la Liga de Defensa de la Ciudad de Santa Fe y fue herido en combate en una pierna" (Rivanera Carlés, 1986, p.3).
} 
que tuvieron los judíos. Negar este aspecto esencial, excluirlo por miserable temor o "táctica", es impropio de quien pretenda analizar seria y objetivamente los sucesos y que, además, se respeta a sí mismo. Por otro lado, son los judíos quienes han introducido esta cuestión negando mentirosamente toda responsabilidad en el alzamiento y acusando de pogroms y asesinatos de inocentes israelitas a las fuerzas policiales, militares $\mathrm{y}$ civiles que actuaron en el aplastamiento del mismo. (Rivanera Carlés, 1919, p.5)²

La lectura del campo nacionalista responde al punto de vista de los sectores sociales que impulsaron la represión y que fue sostenido desde las esferas oficiales. Ahora bien, si retomamos las ideas de Traverso (2012) acerca de la controversia historiográfica, es claro que el objeto de estudio puede ser abordado desde una perspectiva diferente:

Cuando los historiadores adoptan el punto de vista de los vencedores $[\ldots]$ caen siempre en un esquema providencial fundado en una interpretación apologética del pasado. En cambio, los historiadores que se inscriben en el campo de los vencidos vuelven a examinar el pasado con una mirada más aguda y crítica. A corto plazo -afirma [Reinhart Koselleck]- 'puede que la historia esté hecha por los vencedores pero, a largo plazo, las ganancias históricas de conocimiento provienen de los vencidos'. (pp.28-29)

Frente a esa posición inicialmente dominante, hay que señalar la importancia creciente que las redes memoriales adquirieron con el correr de los años, para instalar el tema como una lucha sustentada en lo que Walter Benjamin denomina, en su tesis decimosegunda, "la imagen de los abuelos esclavizados"3 (p.197) que, según el filósofo, debería ser el verdadero motor de la emancipación. Se trata, en efecto, de una construcción progresiva y colectiva, que podría también analizarse a partir de lo que Michel Foucault denominó saberes sujetos entendidos, en primer lugar, como "contenidos históricos que fueron sepultados o enmascarados dentro de coherencias funcionales o sistematizaciones formales" (p.17).

Es desde este punto de vista de "los vencidos", en el que la Semana Trágica ha sido objeto de estudio y de reflexión por parte del campo historiográfico vinculado con la izquierda y el movimiento obrero en la Argentina. Se busca analizar tanto la cronología de los acontecimientos

\footnotetext{
${ }^{2}$ Esta línea historiográfica vinculada con el nacionalismo sigue, hasta el día de hoy, sosteniendo la misma hipótesis de que las acciones represivas fueron una reacción a los intentos por conjurar el peligro revolucionario, al que asocian indefectiblemente con líderes judíos extranjeros infiltrados en el territorio nacional. Como ejemplo de esa persistencia, puede consultarse el reciente artículo de Enrique Díaz Araujo "Mitos y verdades sobre la Semana Trágica" donde el autor menciona una supuesta manipulación de los datos históricos con el afán de ocultar los verdaderos orígenes y peligros de los hechos de enero de 1919: "Sin embargo, la mayor carencia informativa reside en la ausencia de mención de los líderes de la violencia. Porque ésta fue una insurrección dirigida por anarcosbolcheviques locales conectados con agentes soviéticos enviados por la Rusia Soviética -análoga a los putsch promovidos por los soviets en Hungría (Bela Kun), en Munich, Berlín (espartaquistas) y Hamburgo". Y más adelante, agrega, en su intento por justificar la violencia ejercida sobre vastos sectores de la población: "O sea, que no hay efecto sin causa. Sin causa proporcionada. A la acción revolucionaria se sigue la represión (legal o clandestina, como aconteció en 1976). Luego, si los revolucionarios desataban su guerra irregular, a la sociedad y sus autoridades sólo les quedaba una alternativa de hierro: o se rendían ante el embate revolucionario o lo contestaban y contenían. Pues, esto último es lo que pasó en enero de 1919: se reprimió una previa rebelión. De ahí que explayarse sobre los excesos de los métodos represivos, sin mencionar la anterior actividad revolucionaria, configure una actitud sectaria y antihistórica".

${ }^{3}$ Todas las citas de las tesis de Sobre el concepto de historia de Walter Benjamin provienen de la edición comentada de Reyes Mate, publicada con el título de Medianoche en la historia.
} 
como sus consecuencias éticas y legales. Asimismo, se tiende a poner de manifiesto la desmedida represión y el oprobioso silencio cómplice de las autoridades estatales y, fundamentalmente, se busca resaltar la impunidad de la que gozaron los perpetradores de los abusos (que, según se puede apreciar en los fragmentos del libro de Rivanera Carlés transcriptos, son exaltados como héroes por el campo nacionalista).

En línea con esa perspectiva, como un subcampo dentro del campo de los vencidos, se desarrolla un punto de vista específicamente judeo-argentino, para el cual los eventos también pueden ser estudiados y analizados poniendo de manifiesto el hecho de que representan la importación de la violencia antisemita, en una versión muy radical y en una magnitud desconocidas hasta entonces en el territorio nacional. Según esta perspectiva, todas las ilegalidades cometidas en contra de la población judía (arrestos masivos e injustificados, torturas, asesinatos, violaciones, robos, allanamientos ilegales, destrucción de documentación, incendio de bibliotecas, archivos y, en general, de edificios donde funcionaban diferentes instituciones vinculadas con la vida judía en la Argentina) no deben ser considerados únicamente como "excesos de los métodos represivos" (Díaz Araujo, 2019) en contra de las manifestaciones obreras, sino que pueden ser también entendidos como crímenes de odio, dirigidos en contra de los miembros de dicha colectividad.

El pogrom de la Semana Trágica, explica Daniel Lvovich, "constituye un caso testigo capaz de mostrar la potencia que las representaciones sobre el enemigo pueden imprimir a las prácticas, una vez que la convicción sobre la peligrosidad de sus intenciones se apodera de un sector de la sociedad"4 (134). Entre otras conclusiones, es indudable que el pogrom fue posible gracias a la complicidad de los poderes del Estado y que, entre sus consecuencias más funestas, dejó un número nunca esclarecido de víctimas fatales 5 .

Lo cierto es que, recortado del conjunto de los eventos, el asesinato masivo de judíos adquiere una relevancia particular tanto por el ensañamiento, como por la serie de implicancias histórico-culturales que se ponen de manifiesto. En tanto se vincula, al mismo tiempo, con la violenta represión del movimiento obrero (que fue el desencadenante original de las acciones sanguinarias y que no iba dirigido específicamente en contra del colectivo judío) y con la representación estigmatizante del judaísmo, que lo suele presentar como un factor de desestabilización dentro de las sociedades occidentales y cristianas, el pogrom pone de manifiesto una serie de elementos ideológicos que cristalizan en la masacre, pero que necesariamente estaban en circulación desde mucho tiempo antes.

El contexto internacional, post revolución bolchevique, no alcanza para dar cuenta de la reacción estatal y para-estatal de enero de 1919: como señala Lvovich, en varias ocasiones (incluso antes de octubre de 1917), había surgido el miedo a una revolución obrera sin que la

\footnotetext{
${ }^{4}$ Koshmar, el texto de Pinnie Wald que forma parte del corpus estudiado en las páginas que siguen, comparte esta misma hipótesis. Además de estar dedicado a "la memoria de los caídos" el autor comienza el libro con una referencia histórica sobre las revoluciones en el continente europeo, lo cual se refleja en la actitud de la burguesía que "estaba aterrorizada; pensaba que su fin se acercaba. Un espectro rojo se agitaba ante sus ojos. Veían por doquier una conjura maximalista; no dudaban de que, en algún escondite recóndito, se agazapaba el dictador maximalista, de cabellos desgreñados, poniendo a punto el plan de la rebelión" (p.41).

${ }^{5} \mathrm{Al}$ respecto, cfr. "El pogromo de la Semana Trágica: ¿un olvidado de la esfera pública?”, donde Leonardo Senkman propone múltiples hipótesis de análisis relacionadas con el colectivo judío y con el olvido oficial y comunitario a que fue sometida la memoria del pogrom: "El centenario de la Semana Trágica es ocasión propicia para volver a conocer mejor, no tanto la masacre o escenas siniestras del pogromo, sino más bien indagar la pérdida, el blanco, la ausencia definitiva de las cosas desaparecidas de las víctimas; también inquirir la razón del olvido de quiénes fueron los victimarios y de sus cómplices estatales".
} 
reacción conservadora llegara a los extremos de la Semana Trágica. En otras palabras, la represión no hubiera alcanzado la magnitud que tuvo si no se hubiera logrado asociar la huelga obrera con las representaciones de un judaísmo supuestamente complotado para perjudicar a la Nación:

En este contexto [la represión violenta de las luchas obreras] se inscriben las persecuciones y la violencia ejercida contra personas y organizaciones judías, a las que se caracterizaba como responsables de los sucesos no sólo como resultado del desplazamiento semántico entre los conceptos de ruso y judío -factor tantas veces postulado como explicación- sino también a causa de unas representaciones conspirativas sobre el judaísmo que alcanzaron verosimilitud al calor de los sucesos. (Lvovich, p.135)

Según lo señalado, y en el marco conformado por las posiciones antagónicas en la controversia historiográfica cabe preguntarse, por una parte, cómo se configura a cien años de los sucesos, la red de la memoria del campo de los vencidos y, por otro lado, cómo intenta responder al discurso antagónico y oficial que, como hemos visto, aún sigue justificando la masacre. Buscamos aquí emprender el análisis de tres obras que abordan los hechos de enero de 1919: el corpus gira sobre un eje que permite trazar una línea que va de la intención abiertamente testimonial en Koshmar (1929) de Pinnie Wald, pasando por la memoria-ficcional en El arresto (2001) de Perla Suez hasta llegar a María Domecq (2007) de Juan Forn, novela encuadrada en el concepto de autoficción, es decir:

un subgénero híbrido o intermedio que comparte características de la autobiografía y de la novela. En ellas se alteran las claves de los géneros autobiográfico y novelesco y el pacto se concibe como el soporte de un juego literario en el que se afirman simultáneamente las posibilidades de leer un texto como ficción y como realidad autobiográfica. (Musitano, p.104) ${ }^{6}$

\footnotetext{
${ }^{6}$ La historia del término se origina en la década de 1970, cuando el escritor y crítico francés Serge Doubrovsky acuñó la expresión para calificar una novela suya titulada Fils (1977). Doubrovsky buscaba, tanto con la novela como con la nueva clasificación, poner en duda algunas teorías académicas relativas a los pactos de lectura y a la figura del escritor como garante último del texto, que surgieron especialmente de las afirmaciones de Philippe Lejeune en Le pacte autobiographique (1975). En ese estudio, y en reformulaciones posteriores, Lejeune intentó dar cuenta de la autobiografía como un género contractual, que depende de "que coincidan la identidad del autor, la del narrador y la del personaje" (El pacto autobiográfico 52). La afirmación de Lejeune de que la autobiografía se opone a la novela en primera persona a partir de los recursos que asignan la identidad (fundamentalmente, el nombre del autor al pie del texto), fue el punto de partida para que Doubrovsky comenzara su acción estéticocrítica, presentando una novela y un neologismo que buscaban romper la frontera señalada. Sin lugar a dudas, uno de los trabajos más completos sobre el tema es la tesis doctoral de Vincent Colonna titulada "L'autofiction (essai sur la fictionalisation de soi en Littérature)", que data de 1989, en la que explora las posibilidades analíticas del término autoficción. En el mundo hispanohablante, uno de los críticos más destacados sobre el tema es Manuel Alberca, quien ha trabajado el concepto en varios artículos y en su libro El pacto ambiguo. De la novela autobiográfica a la autoficción donde, además de definir esta modalidad narrativa, analiza las implicaciones que ésta conlleva para el acto de escribir y de leer. En ese sentido, expresa que la autoficción "está ligada a la quiebra del poder representativo de las poéticas realistas, teorizada por la crítica literaria estructuralista, pues aunque tiene una apariencia realista convencional, en el fondo cuestiona y subvierte de manera sutil, pero efectiva, los principios miméticos" (50).Para un panorama completo del origen, desarrollo y actualidad del término, puede consultarse el
} 
En concreto si, por un lado, el corpus está conformado por obras que comparten un referente histórico; por otro lado, proponen diferentes modos de relación con ese referente y, en consecuencia, de construcción del recuerdo a través del texto literario: Wald es un testigo y víctima de la represión que da su testimonio; Suez es hija de un sobreviviente cuyas memorias transforma en una novela y Forn es bisnieto de uno de los miembros fundadores de las guardias blancas, secreto que se encargará de ventilar con el afán de expiar culpas.

Si como explica Musitano "en la autoficción, a diferencia de la autobiografía, hay una potenciación de los mecanismos del recuerdo en detrimento del carácter sistemático y organizativo de la memoria" (p.105), entonces el corpus elegido podría permitir reflexionar sobre las formas en que la literatura, la memoria y el conocimiento histórico se vinculan y se influyen activamente cuando ponen en juego los recuerdos personales de los testigos directos y los relatos heredados por las nuevas generaciones, a medida que pasa el tiempo.

Es preciso añadir que esta lectura de la novela de Perla Suez y, fundamentalmente, de la de Juan Forn se encuentra, por una parte, orientada hacia una visión redencionista en los términos propuestos por Benjamin en la tesis decimosegunda, como hemos visto antes. Por otra parte, se vincula con el concepto de posmemoria, desarrollado por Marianne Hirsch para referirse a "the experience of those who grow up dominated by narratives that preceded their birth, whose own belated stories are evacuated by the stories of the previous generation shaped by traumatic events that can be neither understood or recreated" (22). Al caracterizar esta experiencia, Hirsch tenía en mente, especialmente, a los descendientes de los sobrevivientes de la Shoá, aunque sus ideas son aplicables también al caso que nos ocupa: la experiencia de la posmemoria, permite poner de relieve una visión de la historia performativa, construida a partir de la conciencia que parte desde los "nietos liberados" de los que habla Benjamin, aunque no como un resultado en sí mismo, sino como búsqueda activa de la imagen de los "abuelos esclavizados" a la que nos hemos referido antes.

En otras palabras, el análisis de las obras señaladas permite tanto considerar las hipótesis sobre las relaciones entre recuerdo, memoria, posmemoria y ficción, como revisar el tratamiento de un tema menos abordado por la literatura y menos complejo en cuanto a los códigos de representación que la Shoá, pero cuya recuperación se ha constituido como un deber de las generaciones posteriores, en tanto encarna el ideal a concretar de "la clase vengadora que lleva hasta el final la tarea de liberación en nombre de las generaciones vencidas" (p.197)7.

Retomando el concepto foucaulteano de los saberes sujetos, podemos insistir en la importancia de su recuperación a través del testimonio, de la memoria heredada y de la conformación de una red temática, en tanto se trata de:

artículo "En busca de la unidad perdida: sobre dos autoficciones poéticas argentinas" de Enzo Cárcano, en especial los apartados iniciales.

${ }^{7}$ Por su parte, Enzo Traverso, intenta zanjar las objeciones de Max Horkheimer a la consideración de Walter Benjamin acerca del pasado como una experiencia inacabada y, por lo tanto, teológica. La disputa entre ellos, explica Traverso, "evoca ciertas tensiones que atraviesan la historiografía contemporánea: tensiones entre historia y memoria, entre la toma de distancia propia del enfoque histórico y la subjetividad, hecha de inquietudes y reviviscencias, de recuerdo y de representaciones colectivas que habitan en los actores de la historia" (p.30). A partir de la tesis novena de Benjamin, la del Ángel, agrega: "Auschwitz nos impone mirar la historia como un campo de ruinas, mientras que el gulag nos prohíbe cualquier ilusión o ingenuidad con respecto a las interrupciones mesiánicas del tiempo histórico" (p.30). 
toda una serie de saberes que habían sido descalificados como no competentes o insuficientemente elaborados: saberes ingenuos, jerárquicamente inferiores, por debajo del nivel de conocimiento o cientificidad requerido. Y la crítica se efectuó a través de la reaparición de estos saberes bajos, no calificados o hasta descalificados (los del psiquiatrizado, del enfermo, del enfermero, del médico que tiene un saber paralelo y marginal respecto del saber de la medicina, el del delincuente), de estos saberes que yo llamaría el saber de la gente (y que no es propiamente un saber común, un buen sentido, sino un saber particular, local, regional, un saber diferencial incapaz de unanimidad y que sólo debe su fuerza a la dureza que lo opone a todo lo que lo circunda). (Foucault, 1996, p.18)

Fundamentalmente, lo que surge de las obras que analizaremos, es la conciencia de sus autores de estar escarbando desde el campo de los vencidos para reconstruir sus historias o, más específicamente, para denunciar los excesos del poder represivo. Esto constituye, retomando las palabras de Traverso antes citadas, una "ganancia histórica de conocimiento" $(2012$, p.29) porque amplía el saber y porque (aquí Traverso sigue a Benjamin) "significa entrar en resonancia con la memoria de los vencidos, cuyo recuerdo se perpetúa como 'una promesa de redención' insatisfecha" (p.28).

\section{El presidente del soviet argentino: la detención de Pinnie Wald}

Koshmar (Pesadilla) ${ }^{8}$ de Pinnie o Pedro Wald, supone un primer grado de cercanía sobre el referente extratextual, ya que se trata de una narración asentada en el pacto de veracidad convencional de la autobiografía producida, además, por un periodista. En efecto, se trata de las memorias de Wald sobre sus vivencias en enero de 1919. Dos peculiaridades hay que señalar, porque ponen de relieve la marginalidad, el poco interés y el manto de olvido que se había cernido sobre la Semana Trágica: la primera, es el hecho de que Wald haya publicado ese testimonio diez años después del pogrom en el que casi pierde la vida; la segunda, es que lo haya publicado en ídish, lo que mantuvo la obra alejada del público que no hablaba esa lengua ${ }^{9}$. Como hipótesis al respecto, puede postularse que el clásico prejuicio estigmatizante de la supuesta extranjería de los judíos, lo mismo que el desinterés general por recordar el pogrom de 1919,

\footnotetext{
${ }^{8}$ Koshmar (קאשמאר) significa "pesadilla" en español (aunque es un término menos habitual que נייטמער /naitmer/). En un testimonio recogido en el documental Un pogrom en Buenos Aires, Elihau Toker explica que el origen del término koshmar es francés y que remite a un estadio primitivo del ídish. En efecto, pesadilla en francés se dice cauchemar. Cabe destacar que términos derivados de la misma raíz existen, además, en algunas lenguas eslavas, como en el ruso (кошмар) y en el polaco (koszmar).

${ }^{9}$ Hecho éste que, además, introduce la tensión acerca de la adscripción del texto a la literatura argentina. La traducción al castellano fue realizada en 1987 para ser incluida en un volumen antológico, cuyo elocuente título era Crónicas judeoargentinas - Los pioneros en ídish: 1890-1944. Posteriormente, en 1998, Pedro Orgambide lo reeditó por separado en la editorial Ameghino y le agregó como subtítulo "Una novela de la Semana Trágica" dato que, como veremos más adelante, concierne a la discusión sobre la naturaleza del texto de Wald. Finalmente, al conmemorarse el centenario de la Semana Trágica, Koshmar fue reeditado en 2019 por la editorial Astier, en un volumen donde aparece acompañado por una serie de estudios críticos, a los que se suma otra fuente primaria de relevancia: las notas de la viajera norteamericana Katherine Dreier tituladas "La huelga general, Buenos Aires, enero de 1919", cuya recuperación constituye un valioso aporte y un interesante contrapunto de perspectivas con el testimonio de Wald.
} 
seguían pesando sobre Wald cuando previó que el único público posible para su testimonio sería el ídish hablante.

A partir de esos datos, resulta particularmente interesante analizar algunas operaciones críticas sobre la tensión acerca de cómo se inserta Koshmar en el campo literario argentino. Puntualmente podemos señalar que la recepción ha propuesto, en una perspectiva impensable para el propio autor, incluir el libro en una serie literaria, en la que se prioriza el afán de verlo como un antecesor de la no-ficción. Perla Sneh, por ejemplo, recuerda que "aún se discute si Koshmar es novela o crónica o ambas. En ese contexto, hay quien ve en el texto un preludio de lo que más tarde se llamará 'non fiction"'"10 $(2019, \mathrm{p} .12)$.

Debería hacerse notar, sin embargo, que tanto Rodolfo Walsh como Truman Capote, para mencionar los dos referentes de la no-ficción con los que se asocia a Wald, configuran una tipología textual desde su aparición como cronistas y donde su participación de las acciones narradas es nula o muy marginal. Es decir, sus obras no están centradas en sus propias experiencias ni sus recuerdos (o, para decirlo con más precisión, no están centradas en su intervención personal en los eventos; sino en su vinculación a posteriori con alguno de los protagonistas, que le brindan información sobre lo sucedido). En ese sentido, la distancia entre Koshmar y Operación masacre, es innegable, pero, sobre todo, el esfuerzo resulta poco útil, en tanto pretende realzar los méritos literarios de la primera a través de la importancia de la segunda.

Frente a ese tipo de lecturas, y aunque evita ser categórica señalando que Koshmar "complica la pregunta por el género literario", Perla Sneh precisa que "si hubiera necesidad de establecer el género, éste quizás fuera algo entre el delirio como narración desolada y desoladora y la vigilia insomne de una memoria asediada que enlaza el presente catastrófico con una genealogía siempre amenazada" (p.33).

Koshmar es, fundamentalmente, un relato autobiográfico cuyo autor fue él mismo víctima del pogrom: fue acusado de ser el presidente del futuro soviet argentino y, en base a esa falsa atribución, recibió un trato especialmente cruel ${ }^{11}$. El texto describe parte de las torturas y el modo en que Wald y otros dos prisioneros (a quienes no conocía antes de las detenciones), son exhibidos orgullosamente por las autoridades policiales, que los presentan como los integrantes del triunvirato que estaba destinado a regir el soviet argentino:

Uno de los oficiales internos se enderezó y comenzó a "dar explicaciones":

\footnotetext{
${ }^{10}$ El primero en proponer esa genealogía que conecta a Wald con Walsh fue Pedro Orgambide, en el prólogo de la edición ya mencionada. Leonardo Senkman, recupera y, en gran medida, avala ese punto de vista en su artículo antes citado. Hernán Szwarcbart, en una entrevista acerca de su documental Un pogrom en Buenos Aires, donde recupera fragmentos de Koshmar, apunta en la misma dirección que Orgambide: "En cuanto a Wald, el suyo es un texto testimonial pero es una novela, no lo escribió como ensayo, es una especie de registro de real fiction, ese recurso que apareció posteriormente". Gabriel Lerman, responsable de la más reciente reedición de Koshmar mencionada en la nota anterior, si bien matiza algunas de estas ideas al referirse a Koshmar como "crónica novelada", luego recupera la opinión de Orgambide: "según Pedro Orgambide, la recreación literaria de Wald era un claro antecedente del nuevo periodismo, lo que para nosotros no era tanto Truman Capote sino Rodolfo Walsh" (7).

${ }^{11}$ Como refiere Gabriel Lerman en la presentación del volumen, el asunto de la detención del "presidente del soviet Pedro Wald", ocupó la primera plana de los diarios durante varias jornadas (p.8). En la entrevista antes mencionada, Szwarcbart declara: "La foto de Wald apareció en La Nación; la noticia era que habían detenido al futuro dictador del primer soviet de la república federal de los soviets argentinos. Es decir, se lo mencionaba como si hubiera formado parte de un complot para tomar el poder e instalar el soviet en el país."
} 
-Este es el triunvirato maximalista...este es el "presidente", aquel es el "ministro de guerra" y el otro "el jefe de la policía".

Los que desfilaban frente a nosotros nos observaban con diversas expresiones en los ojos: dureza, astucia, asombro y estupidez bovina; el oficial seguía "declarando":

-El presidente es el que lanzó la primera bomba y bebió la sangre del soldado, cuyo cuerpo se hizo pedazos; ésta es su manera de proceder...

Tenía ganas de reírme, pero no sé qué suerte de expresión se reflejó a través de mi rostro, con el chichón por encima de mi ojo derecho, los dientes perdidos, la sangre reseca en derredor de los labios y la nariz. (2019, pp.65-66)

La absurda imputación y, sobre todo, el hecho de que pareciera creíble para buena parte de las autoridades políticas y militares y, por supuesto, para un sector importante de la prensa, es una muestra elocuente del funcionamiento del miedo y de las teorías conspirativas, según destaca la hipótesis de Daniel Lvovich que hemos citado anteriormente.

La gravedad de la situación se puede apreciar en varios pasajes del texto que registran las visitas de amistades que Wald recibe durante el cautiverio y que, en general, son decepcionantes desde su perspectiva. Un caso paradigmático es el de la llegada de Alfredo L. Palacios al frente de una comisión encargada de velar por el bienestar de los presos. Por el respeto y el peso específico de la figura del líder socialista, en un primer momento representa para el prisionero la esperanza de liberación. Sin embargo, cuando Palacios procede a interrogarlo apelando a los mismos argumentos de los represores, Wald no esconde su desánimo:

Desapareció, de pronto, de ante mis ojos, aquel Palacios que había sentido tan cercano a mi corazón y que hacía tan poco tiempo había encendido una esperanza vital; ahora estaba delante de mí una de aquellas personalidades, uno de los visitantes privilegiados, que venían a observarme, tal como se contempla una curiosidad o una rareza, o para interrogarme más detalladamente. Esto me enojó. (p.90)

Perla Sneh repara también en este pasaje y apunta que Wald "rápidamente racionaliza la situación y concluye que es una medida precautoria, [pero] no por eso se siente menos herido" (2019, p.27). Sin embargo, la verdad es que la sospecha, el escepticismo y los resquemores se sostienen y, más adelante, vuelven a repetirse frente a otros visitantes. Wald comprende, rápida y dolorosamente, que su caso es más complejo por ser un inmigrante de origen judío, motivo por el cual no duda en comparar el trato que le dan las autoridades con el accionar de la Inquisición española:

Me pinchaban con alfileres, me quemaban las puntas de los dedos con fósforos encendidos. Yo ya no albergaba esperanza alguna de poder salir de sus manos con vida. Una hora más de martirios, otra hora de torturas como las practicadas por el Santo Oficio y moriría...Pero mientras esta vida mía se encontrase en mis propias manos, ¡no se las entregaría a ellos! (p.69)

Podemos aquí recuperar el concepto de la genealogía amenazada propuesto por Perla Sneh, en tanto Wald apela no a una memoria que se pretende idéntica a los hechos, sino a una serie que superpone épocas y espacios diferentes pero afines. El problema de la dimensión de la memoria en Koshmar, entonces, se vincula con el pacto de lectura con el que Wald pretende que 
su texto sea abordado. Si es como la memoria de una víctima, le cabe primordialmente una función testimonial, lo cual resulta irrefutable. Pero al mismo tiempo, se trata de una memoria que la identidad judía trae consigo desde Europa y que aporta paulatinamente al caudal literario argentino. En otras palabras, es este enfoque el que permite pensar en el texto de Wald como un antecedente, pero no de la serie de la no-ficción antes referida, sino de una diferente, basada en lo que la propia Sneh caracteriza como un estado de alerta que permea en la "escritura judía de la catástrofe de un modo singular y, por la pluma de Wald, viene a impregnar la escritura argentina" (p.33).

Sobre el valor esencial del testimonio y de la diferencia con otros tipos de producciones, podemos citar nuevamente a Beatriz Sarlo quien, en el análisis de la producción autofictiva y posmemorial, expresa del siguiente modo:

Vivimos en una época de fuerte subjetividad y, en ese sentido, las prerrogativas del testimonio se apoyan en la visibilidad de que 'lo personal' ha adquirido como lugar no simplemente de intimidad sino de manifestación pública. Esto sucede no sólo entre quienes fueron víctimas, sino también y fundamentalmente en este territorio de hegemonía simbólica que son los medios audiovisuales. Si hace tres o cuatro décadas el yo despertaba sospechas, hoy se le reconocen privilegios que sería interesante examinar. De eso se trata, y no de cuestionar el testimonio en primera persona como instrumento jurídico, como modalidad de escritura o como fuente de la historia, a la que en muchos casos resulta indispensable, aunque le plantee el problema de cómo ejercer la crítica que normalmente ejerce sobre otras fuentes. (2005, p.25)

En resumen, aunque es innegable que la misma estructura narrativa de Koshmar junto con otros datos contextuales (como el hecho de haber sido publicado una década después de los sucesos y en ídish), promueven una lectura en capas, más variada y enriquecedora, no debería perderse de vista la función inicial de denuncia con la que el texto fue concebido ${ }^{12}$. Es desde ese lugar, y adelantándonos a lo que especificaremos en las próximas secciones de este trabajo, donde Koshmar sienta, en el campo de los vencidos, la bases para sustentar la controversia historiográfica a partir de la imagen de los abuelos esclavizados, pero también donde marca una diferencia irreductible con los otros textos que componen el corpus.

\section{El arresto: la memoria heredada y la memoria ficcionalizada}

El arresto (2001) de Perla Suez es una novela protagonizada por Lucien Finz, especie de alter ego del padre de la autora. La narración es fragmentaria y recupera momentos de la vida en Santa Clara y, posteriormente, los sucesos de 1919 en Buenos Aires durante los cuales el protagonista es arrestado y torturado. Además, si tenemos en cuenta la voz, se intercalan pasajes de un narrador heterodiegético con otros en los que el narrador es homo-autodiegético. Estos últimos se configuran como fragmentos de cartas que Lucien dirige a Vasili, su padre, pero que

${ }^{12}$ Especialmente si se consideran otros textos que giran en torno de la Semana Trágica, pero cuyo pacto de lectura es totalmente diferente, incluso del resto de las obras que componen el corpus analizado en estas páginas. Por ejemplo, y para mencionar un grupo bastante heterogéneo, los cuentos "Mate amargo" de Samuel Glusberg, "Una semana de holgorio" de Arturo Cancela y la novela En la semana trágica de David Viñas. 
luego se revelarán como sus pensamientos, una suerte de monólogo interior con un interlocutor figurado ${ }^{13}$.

En una entrevista publicada en Página/12, Suez ha confesado que la de El arresto: "Es la historia de mi padre (...). Lo estoy viendo, lo puedo ver ahora: recién llegado a capital en el '19 escapando de las hordas de la Liga Patriótica por judío y más tarde a sus 80 años contándome cómo se escondió en la Richmond de Florida para que no lo maten".

De este modo, queda claro que la autora convierte algunos elementos de los recuerdos de su padre en la base para idear las memorias de Lucien Finz que, a su vez, serán escritas por su hija (se presentan como el texto que leemos). En efecto, el recurso metaficcional se vuelve más complejo, a partir de una aclaración que aparece en la página final del libro: "Mi padre, Lucien Finz, trabajó como médico rural cerca de Villa Clara, donde transcurrió su vida de niño. Iba a escribir sus memorias, pero no llegó a concretarlas" (p.90). Este comentario de la presunta escritora tiene un llamado a pie de página, donde se lee: "Del manuscrito que lleva la firma de Leonora Finz, encontrado recientemente en la biblioteca popular Lucienville, Basavilbaso, Entre Ríos, 29 de julio de 2001" (p.90). Por lo tanto, el artefacto ficcional diseñado por Suez (Lucien Finz como alter ego de su padre y Leonora como su propio alter ego) supone un mecanismo de abismamiento tras el cual, como dijimos, se ocultan las memorias de su propio progenitor.

A pesar de la fragmentación de la materia narrativa, el nivel mimético es preciso en muchos momentos de la trama. Esto se debe a una serie de recursos, entre los cuales hay que señalar la inclusión de intertextos que son, o que simulan ser, reproducciones facsimilares de diferentes documentos, dispuestos para aumentar el efecto de verosimilitud. Tal es el caso de la transcripción de una página completa del Sidur o libro de rezos, que aparece en hebreo (31) y, fundamentalmente, del sumario policial, donde consta el orden del día con la novedad del arresto de Lucien ${ }^{14}$ (pp.71-73).

Ahora bien, tanto el recurso de convertir las memorias del padre en las de Finz a través de la escritura de Leonora, como el de la inclusión de los paratextos, se complementan con una serie de detalles que coinciden con testimonios reales de la época, como el aportado por Wald en Koshmar. Entre otras coincidencias, podemos destacar las descripciones del proceso de detención, la burocracia estatal que pretende darle legalidad a la violencia ejercida por sus representantes y, finalmente, los métodos de amenaza y tortura ejercidos en las instalaciones de la policía:

Lucien escucha pasos que vienen por el pasillo. Pasos de hombre que se arrastra cansado. Un espectro cruza lentamente delante suyo y lo mira. Las manos esposadas, un ente que hace pocos días se llamaba Luigi Melle. Lucien no hace más que buscarlo con la mirada; ojos huecos, agujeros vacíos. Está encorvado. Le clavaron agujas en la cara,

${ }^{13}$ Cuando, después de permanecer prisionero, Lucien recupera la libertad, el narrador da cuenta de sus pensamientos: "Quiero que sepa, padre, que durante los siete días que duró mi arresto, necesité hablarle, como si le escribiera una larga carta que nunca le escribí, con palabras que nunca usé, y que fueron saliendo de mi boca hasta apagarse" (89).

${ }^{14}$ En su trabajo sobre las visiones literarias de la Semana Trágica, Brigitte Natanson se refiere al asunto de manera errática y confusa, lo mismo que al explicar el juego intertextual que se propone en la novela con el fingido hallazgo del manuscrito: "La precisión metatextual que aparece en la última página ubica el relato en la modalidad de la ficcionalización a partir de memorias. El proceso, que podría ser ficticio a su vez, quizás no lo sea, si consideramos como "prueba" la reproducción (...) del legajo que da cuenta del arresto de Lucien Finz, con fecha del 8 de enero de 1919" (p.113). Si bien la autora, al aludir al legajo como una prueba, matiza su afirmación utilizando comillas, hay que señalar que no explicita la absoluta ficcionalidad del documento ni de las presuntas memorias que acaban de ser leídas. 
lo golpearon brutalmente. El guardia lo empuja para que camine rápido y le grita, jvamos! (p.57)

Si bien el fragmento transcripto hace alusión al trato que recibe Melle, el compañero italiano de Lucien, los detalles coinciden de manera evidente con las descripciones que introduce Wald en uno de los párrafos ya transcriptos. Con esto, no se pretende sugerir que Suez haya recurrido necesariamente al libro de Wald, sino que, como señala con mucha precisión Perla Sneh en el estudio antes comentado: "No faltan otros escritores que, aún sin leer a Wald -o quizás habría que decir: como lectores borgianos de una tradición que desconocen y resguardan- fueron conformando modos propios de lidiar con una historia que se porta aún si no se la conoce" (p.34).

Como "portadora" de la historia de su padre, entonces, y para formular de manera verosímil las memorias de Finz, Suez se ha documentado en fuentes que recogen testimonios sobre las torturas ejercidas por las fuerzas policiales durante los hechos de 1919. Sin embargo, podría sugerirse que el verdadero gesto justiciero no está en la precisión histórica, sino en la restitución de la voz del sufriente. De hecho, no podemos dejar de señalar que la edición consultada lleva en su portada una ilustración del famoso dibujante Tomi Ungerer donde unos soldados, identificados con símbolos nazis, llevan amenazado con una bayoneta a un prisionero que parece ser judío, haciendo palpable esa conciencia de la "catástrofe única que acumula sin cesar ruinas sobre ruinas" (p.155) de la que habla Benjamin en la tesis novena.

El recurso de las memorias fingidas, que son escritas por la hija pero que permanecen abandonadas hasta que una mano anónima revela su origen (a través de la nota a pie con la explicación), constituye otro punto de contacto con Koshmar como testimonio: Suez redime el sufrimiento del padre a través de un manuscrito ficcional, hallado en una pequeña biblioteca popular de las colonias judías de la Mesopotamia.

\section{Vergüenzas, silencios y complicidades: la memoria familiar ventilada}

Finalmente, María Domecq de Juan Forn (2007), supone paso más allá en la conservación de la memoria a través de la reescritura del pasado familiar por parte de las nuevas generaciones, en este caso, a través de la clave autoficcional. A diferencia de la obra de Suez, Forn idea una ficción en la que la acción transcurre en el presente, desde el cual se intenta aclarar un misterio familiar del pasado. El narrador comparte una serie de rasgos con el autor real, incluyendo su nombre, de modo que la verosimilitud se asienta en lo que Manuel Alberca denomina el "protocolo nominal" de la autoficción. Cabe señalar que Forn, nacido en 1959 en Buenos Aires y en el seno de una familia de la elite económico-política argentina ${ }^{15}$, introduce en varias de sus producciones literarias elementos autobiográficos, fundamentalmente para expresar sus disidencias o su malestar en relación con los privilegios que ostentan. En este sentido, no sería apresurado afirmar que ese espíritu de cuestionamiento en relación a la familia alcanza su fuerza

${ }^{15}$ El concepto de elite es entendido aquí en los términos desarrollados por Teun Van Dijk, como "una noción heurística para definir algunos grupos sociales que disponen de recursos de poder específicos (...). Los recursos de poder de las élites pueden ser múltiples e incluyen propiedad, remuneración, control de decisión, conocimiento, pericia, cargo, rango y, además, recursos sociales e ideológicos, como estatus, prestigio, fama, influencia, respeto y similares, según se los otorgue un grupo, una institución o la sociedad en general” (72). 
máxima en la novela que estamos considerando, fundamentalmente gracias a la mencionada identificación entre autor y personaje.

Frente a las obras comentadas en las páginas precedentes, debemos marcar, primeramente, que en María Domecq no hay una intencionalidad de recuperar los hechos en sí mismos, sino que la Semana Trágica aparece, en principio, como un comentario marginal que apunta a desentrañar la participación de un familiar del narrador autoficcional (su bisabuelo) en los hechos represivos de 1919. Segundo, la presentación de esos hechos no se propone ser documental o testimonial ni, tampoco, responde a un intento de generar empatía reivindicatoria, si no, por el contrario y en un gesto característico de la autoficción, busca ventilar un secreto infamante de la propia familia del autor de la novela ${ }^{16}$.

La novela está planteada como una investigación encarada por Juan, el narrador autoficcional, que comienza intentando comprobar una hipótesis bastante pintoresca: la posibilidad de que Manuel Domecq García, su bisabuelo, hubiera inspirado el personaje de Pinkerton en Madame Butterfly de Puccini y, en lo concreto, que tuviera un hijo no reconocido con una mujer japonesa. En su intento por develar ese misterio, se topa con uno mucho más tangible y menos atractivo: su antepasado fue uno de los fundadores de la Liga Patriótica, la guardia blanca responsable de los linchamientos en el barrio judío durante los disturbios de la Semana Trágica. Este hecho, a diferencia de la hipótesis sobre Madame Butterfly, se asienta en una amplia base documental:

Hasta el momento en que el profesor De Marco me mandó sin proponérselo a revisitar el relato mítico de mi familia, yo sabía de la Semana Trágica lo que sabía del resto de la historia de nuestro país: esa clase de conocimiento somero (con mucho más de somero que de conocimiento) que caracteriza al argentino medio (...). Quiero decir que ignoraba la bochornosa participación del almirante en los hechos, el rol que le cupo. (Forn, 2011, p.89) ${ }^{17}$

La investigación de esa participación infame es emprendida en compañía de María Domecq, una prima segunda del narrador, nieta de una hija retrasada del propio Almirante. En sus propias palabras: "Porque era cierto: había, en nuestra familia, una loca en el altillo. Era algo que no se ocultaba exactamente pero tampoco se mencionaba" (Forn, p.35).

El personaje de María Domecq funciona como un enlace que le permite al narrador abrir los ojos a una realidad superadora y que apunta a la redención de las víctimas. Por ser la heredera del apellido pero no de los privilegios, María estaba al tanto del secreto que vivía solapado detrás de la figura del antepasado famoso y que se relaciona con la memoria colectiva y popular de los argentinos: “Sabés quién se llamaba como vos? ¿Sabés el flor de turro que tenía ese apellido?" (Forn, p.90). La paradoja se manifiesta en la constatación, expresada por Juan, de que ella, que no

\footnotetext{
${ }^{16}$ Manuel Alberca se refiere en los siguientes términos a esta característica de la autoficción: "Al autor de autoficción no le queda otra salida que mostrar de sí mismo una imagen negativa o degradada para vencer la resistencia del lector. Al presentarse ante éste como débil, sumiso, temeroso, indeciso, ridículo, depresivo o malvado, persigue la cercanía y la complicidad de los lectores. Los gestos de autocrítica y autoderrisión son actos de aparente sumisión, incluso de humillación, de un personaje de papel, que, cual sosías, protege a la persona del autor" (280).

${ }^{17}$ La mención del historiador Miguel Ángel De Marco, quien entre otros cargos ocupara el de presidente de la Academia Nacional de la Historia de la República Argentina y que, además, es un reconocido especialista en historia naval, introduce un elemento de importancia para construir la verosimilitud del episodio.
} 
lo había visto nunca en su vida "lo conocía mejor que yo, aunque supiera mucho menos de él" (Forn, p.90). La memoria vicaria, silenciada, se planta frente a la historia oficial y se nutre de ese sustrato conflictivo de conocimientos sujetos de los que habla Michel Foucault:

He aquí, así delineada, lo que se podría llamar una genealogía: redescubrimiento meticuloso de las luchas y memoria bruta de los enfrentamientos. Y estas genealogías como acoplamiento de saber erudito y de saber de la gente solo pudieron ser hechas con una condición: que fuera eliminada la tiranía de los discursos globalizantes con su jerarquía y todos los privilegios de la vanguardia teórica. Llamamos pues "genealogía" al acoplamiento de los conocimientos eruditos y de las memorias locales: el acoplamiento que permite la constitución de un saber histórico de las luchas y la utilización de este saber en las tácticas actuales. (1996, p.18)

Solamente a partir del contacto con la figura de María, de su intermediación y de lo que Foucault llama el acoplamiento de sus saberes con los de la Historia oficial, los elementos del pasado familiar se resignifican y llegan a adquirir su verdadera dimensión. En otras palabras, es María quien abre a Juan las puertas de un entendimiento profundo de los hechos y quien le permite encadenar los eslabones perdidos:

yo, que me enorgullecía de haber expuesto a la luz pública ese pequeño oprobio privado [el del hijo japonés del almirante], había sido incapaz de ver la verdadera bomba: que el presunto Pinkerton de Puccini había sido, en la vida real, el responsable del primer pogrom en territorio argentino, el organizador del primer grupo paramilitar a gran escala en la historia de nuestro país. (Forn, p.91)

La investigación sobre el antepasado, lo llevará a descubrir que si bien Domecq García fue responsable de las muertes, (como mínimo, en tanto ideólogo y articulador de las guardias blancas), nunca recibió un castigo. Por el contrario, terminó su carrera con los grados y honores militares más altos y luego de haber sido ministro de marina durante el gobierno de Alvear: es considerado un héroe por su participación en la guerra ruso-japonesa y, todavía hoy, un astillero lleva su nombre ${ }^{18}$.

Apenas esbozada la sospecha, entonces, Juan se dedica a estudiar sistemáticamente el relato de la historiografía oficial para contrastarlo tanto con la tradición familiar, fijada por su propia abuela, como con el relato disruptivo, introducido por María. El resultado será, además del descubrimiento infamante, el surgimiento de una empatía con el campo de los postergados (la rama bastarda de la familia) y con el campo de las víctimas del pogrom (del cual su bisabuelo participó como perpetrador). A través de ese mecanismo tenso, que denuncia la complicidad y el silencio de los vencedores, lo que sucede es que se promueve el surgimiento de una nueva memoria, que coincide con la de los silenciados de la familia y de la historia.

Además de fijarse puntualmente la figura de su antepasado, la novela reflexiona acerca del relativo olvido al que la Semana Trágica ha sido sometido. Aquí no se trata de exponer la memoria personal o de un antepasado, para denunciar los atropellos recibidos; sino que se trata

${ }^{18}$ Se trata del astillero Ministro Manuel Domecq García, ubicado en la Ciudad de Buenos Aires y orientado especialmente a la construcción y reparación de buques submarinos. El mismo fue fundado en 1977 como una empresa mixta, compuesta por capitales públicos y privados. 
de una reflexión acerca de cómo se ha construido la Historia, a partir de omisiones e injusticias. Retomando la cita de Traverso, podemos decir que Juan Forn escarba en y desde el campo de los vencedores, pero no con una intención reivindicatoria (como la de Rivanera Carlés), sino para exponer las infamias que la propia estirpe ha cometido $y$, sobre todo, para denunciar el silencio cómplice de las generaciones posteriores.

\section{Conclusiones}

A lo largo de las páginas precedentes, hemos propuesto un recorrido a través de tres obras que tematizan los eventos conocidos como Semana Trágica acaecidos en enero de 1919 y que incluyeron, como se ha señalado, una violenta represión al movimiento obrero y un pogrom en contra de los ciudadanos judíos.

Las obras analizadas coinciden por estar estructuradas a partir de un yo que participa de los hechos y que aparece enunciado a nivel textual como protagonista en cada una de las tres narraciones. En el caso de Koshmar, la configuración del texto aparece vinculada con la función testimonial y con la voluntad de reconstruir los sucesos desde una posición narrativa sustentada en la participación, en tanto víctima de la represión, de su autor. En cambio, las dos novelas comentadas a continuación, representan otros dos modos de elaboración memorística: la autobiografía ficcional y la autoficción, que proponen pactos de lectura muy diferentes.

En relación con Koshmar, e incluso si se quisieran destacar los rasgos novelísticos del texto, no debería perderse de vista el sustrato histórico-biográfico que lo fundamenta. La lectura debería partir, ante todo, de la conciencia de que es un sobreviviente quien escribe para dar su testimonio (y, en ese sentido, no debería ser tratado de manera diferente a los testimonios de los sobrevivientes de otras masacres o genocidios). En los otros dos casos, el valor de verdad, aunque secundario a la narración y al pacto ficcional propuesto, supone también un intento por recuperar un hecho bastante marginado de la conciencia colectiva. Se trata de un aspecto que, a su vez, podría relacionarse con una línea de la nueva narrativa latinoamericana que busca leer el presente a partir de la recuperación del pasado olvidado o de una perspectiva diferente a la que impone la historiografía tradicional, para reponer sus silencios y omisiones cómplices con el poder. Como se señaló al comenzar, a pesar de las diferencias ostensibles en sus concepciones, propósitos, estructuras e, incluso, a pesar de la distancia temporal que media entre ellas, se vinculan por establecer una red temática vinculada con los saberes sujetos del campo de los vencidos.

En términos generales, lo que surge de esta línea es una tensión que descoyunta el relato conformista de la Nación que pretende, en su mirada autocomplaciente e idealizada, ser un crisol de razas. Es esa visión, ese relato aplanador, el que queda expuesto y seriamente cuestionado a través de las obras analizadas. El propio Wald lo expresa con estas palabras en Koshmar:

La historia que aprendí en la escuela decía que la barbarie está en el campo y la civilización en la ciudad. Lo que sucedió esta semana aquí, me hace ver a Buenos Aires como un mar de barbarie, una gran ciudad donde se ven costumbres perversas y se escucha un irritante murmullo que hace que uno se transforme en un extraño en su propio país. Quiero que sepa que no voy a corroborar una culpa que no tengo. (p.64) 
Diego Eduardo Niemetz

Se trata, como señalamos antes, de saberes descalificados cuyo acoplamiento (para usar el término propuesto por Foucault) con las versiones canónicas es siempre problemático: la memoria del sobreviviente que escribe en ídish, porque a casi nadie parece importarle lo que le sucedió; el relato en que el padre transmite, como un recuerdo lejano (en el tiempo y el espacio), lo que le sucedió y que mucho después es, por fin, escrito por la hija; y, por último, el quebrantamiento de la memoria de la familia, recuperando empáticamente las narrativas silenciadas de las víctimas, de la locura y de la bastardía, para, después de todo, legitimarlos y reivindicarlos desde el lado de los perpetradores.

A pesar de las diferencias en relación a los mecanismos narrativos empleados, que parecen estar asentados sobre la distancia que media entre los hechos históricos y el acto de escritura, los ejemplos analizados tienen en común el haber sido formulados desde una perspectiva que avanza desde el margen. Es en este sentido que podemos afirmar, nuevamente siguiendo a Traverso, que estamos frente a un tipo de aproximación que no reemplaza un método de análisis histórico, pero que "orienta y define el objetivo de la investigación, en las antípodas de la concepción actualmente dominante de la historia como "experticia" (p.28). Apelando a una red temática que vincula épocas, realidades y procedimientos de la memoria y de la fícción que podrían parecer muy diferentes, los autores trazan líneas que son retomadas, reformuladas y resignificadas con nuevas resonancias por otras generaciones, colaborando en hacer realidad aquella promesa de redención sobre la memoria de los vencidos.

\section{Referencias Bibliográficas}

Alberca, M. (2007). El pacto ambiguo. De la novela autobiográfica a la autoficción. Madrid: Editorial Biblioteca Nueva.

Cárcano, E. (2016). En busca de la unidad perdida: sobre dos autoficciones poéticas argentinas. Perífrasis. Revista de Literatura, Teoría y Crítica. 7(13).

Díaz Araujo, E. (2019). Mitos y verdades sobre la Semana Trágica. En: La prensa, 28/09/2019. [On line]: http://www.laprensa.com.ar/481260-Mitos-y-verdades-sobre-la-SemanaTragica.note.aspx. Último acceso: 29/09/2019

Forn. M. D. (2011). Buenos Aires: La página.

Foucault, M. (1996). Genealogía del racismo. Altamira, La Plata.

Galarza, L. (2017). De tu tierra: entrevista a Perla Suez. En: Página/12, 14/5/2017. [On line]: https://www.pagina12.com.ar/37532-de-tu-tierra. Último acceso: 15/4/2019.

Hirsch, M. (1997). Family frames: Photography, Narrative and Postmemory. Cambridge, MA, and London: Harvard University Press.

Lerman, G. (2019). En la tapa del diario. En: Wald, Pinie. Koshmar: Pesadilla. Buenos Aires: Astier, p.7-9.

Lvovich, D. (2003). Nacionalismo y antisemitismo en la Argentina. Buenos Aires: Javier Vergara Editor.

Mate, R. (2006). Medianoche en la historia. Comentarios a las tesis de Walter Benjamin 'sobre el concepto de historia'. Madrid: Trotta. 
Musitano, J. (2016). La autoficción: una aproximación teórica. Entre la retórica de la memoria y la escritura de recuerdos. En: Acta Literaria, $\mathrm{N}^{\circ}$ 52, p. 103-123.

Natanson, B. (2007). Repertorios de una semana: visiones literarias de la 'semana trágica' (Buenos Aires, enero de 1919). Pandora: revue d'etudes hispaniques. ISSN 1632-0514, $\mathrm{N}^{\mathrm{o}} 7$, p. 99-128.

Rivanera Carlés, F. (1986). El judaísmo y la Semana Trágica: la verdadera historia de los sucesos de enero de 1919. Instituto de Investigaciones sobre la Cuestión Judía.

Sarlo, B. (2005). Tiempo pasado: cultura de la memoria y giro subjetivo: una discusión. Buenos Aires: Siglo Veintiuno, 2005.

Senkman, L. (2019). El pogromo de la Semana Trágica: ¿un olvidado de la esfera pública?. En: Nueva Sión. [On line]: http://www.nuevasion.com.ar/archivos/27176. Último acceso: $02 / 11 / 2019$.

Sneh, P. (2019). Pesadilla de Pinie Wald: silencio y transmisión. En: Wald, Pinie. Koshmar: Pesadilla. Buenos Aires: Astier, p.11-37.

Suez, P. (2001). El arresto. Buenos Aires: Grupo Editorial Norma.

Szwarcbart, H. (2007). Un pogrom en Buenos Aires https://www.youtube.com/watch?v=OAWLMcj5y3k. Último acceso: 15/09/2019

Traverso, E. (2012). La historia como campo de batalla: interpretar las violencias del siglo XX. Buenos Aires: Fondo de Cultura Económica.

Van Dijk, T. A. (2003). Racismo y discurso de las elites. Barcelona: Gedisa.

Wald, P. (2019). Koshmar: Pesadilla. Buenos Aires: Astier. 